\title{
The Energy Crisis in Parkinson's Disease: A Therapeutic Target
}

\author{
Mhamad Abou-Hamdan, Emilie Cornille, Michel Khrestchatisky, \\ Max de Reggi and Bouchra Gharib \\ NICN, UMR6184, CNRS, Aix-Marseille University, Marseille
}

France

\section{Introduction}

The energy demand of the brain is very large: it accounts for $20 \%$ of the body's energy consumption, even though its weight is less than $2 \%$ of the total body mass. In the adult, brain energy comes primarily from glucose through oxidative glycolysis. The end product is acetyl-coenzyme A (acetyl-CoA), which enters the mitochondria and feeds into the tricarboxylic acid (TCA) cycle to produce energy in the form of reductants, such as NADH. The chemical energy of NADH is then used by the respiratory chain, or electron transport chain, to synthesize ATP (Fig. 1). Energy depletion is a major factor in the cascade of events culminating in dopaminergic neuronal death in Parkinson's disease (PD). There are two reasons for that. First, a frequent feature of the disease, as well as of other neurodegenerative diseases, is an alteration of glucose metabolism. Second, there is a decrease of mitochondrial respiratory chain activity due to, in particular, inhibition of the electron transport system complex I (NADH-ubiquinone oxidoreductase).

Complex I activity is redox-dependent and thiol-regulated; therefore its inhibition is associated with oxidative stress. Depletion of GSH, a major antioxidant and redox modulator, is observed in the substantia nigra of parkinsonian patients, as well as in the mouse MPTP model of the disease. Conversely, the restoration of GSH levels preserves complex I activity. Accordingly, the maintenance of cellular redox homeostasis by thiol agents protects against nigrostriatal toxicity.

In the case of the alteration of glucose metabolism, the brain has the ability to adapt its metabolism and to increase its reliance on lipids for energy production, through fatty acid $\beta$ oxidation. The process involves a mitochondrial oxido-reductase superfamily with broad substrate specificity. The penultimate step of the process is catalyzed by L-3-hydroxyacylCoA dehydrogenase (HADH II) (EC 1.1.1.35). HADH II overexpression protects against acute brain injury and chronic neurodegeneration. By-products of fatty acid $\beta$-oxidation are the ketone bodies $\beta$-hydroxybutyrate and acetoacetate. When injected into mice or rats, or administered in the form of a ketogenic diet, ketone bodies have a protective role in a broad spectrum of cerebral injuries and diseases.

In the present report, we examine the brain energy metabolism, its alterations associated with PD and how fatty acid $\beta$-oxidation can compensate such impairment. Energy store boosting agents have potential therapeutic properties. Pantethine, the precursor of vitamin 
B5, is one of them, with the advantage of targeting multiple pathways involved in disease process. By itself or by its constituents (Fig. 2), pantethine regulates lipid metabolism, in addition to its anti-oxidant and anti-inflammatory properties, giving rise to the promise of an original therapeutic strategy against PD.

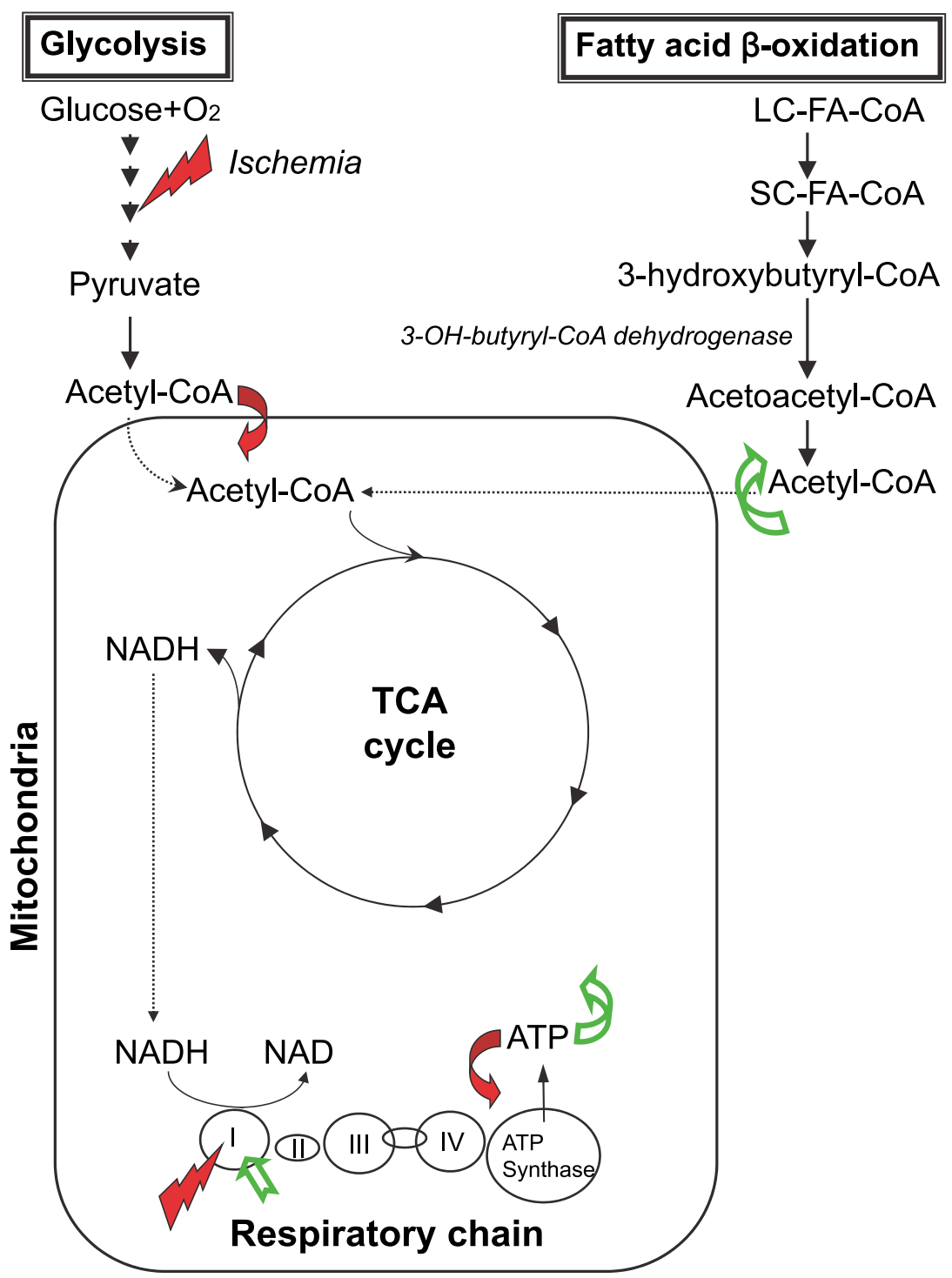

Fig. 1. The energetic pathways. Glycolysis is the major energetic pathway in the adult brain. It is impaired in Parkinson's disease, leading to an energy crisis, which is compensated by fatty acid$\beta$-oxidation. Solid symbols (red) indicate the injuries and alterations occurring in the processes leading to the disease; open symbols (green) indicate the protective effects of pantethine. 


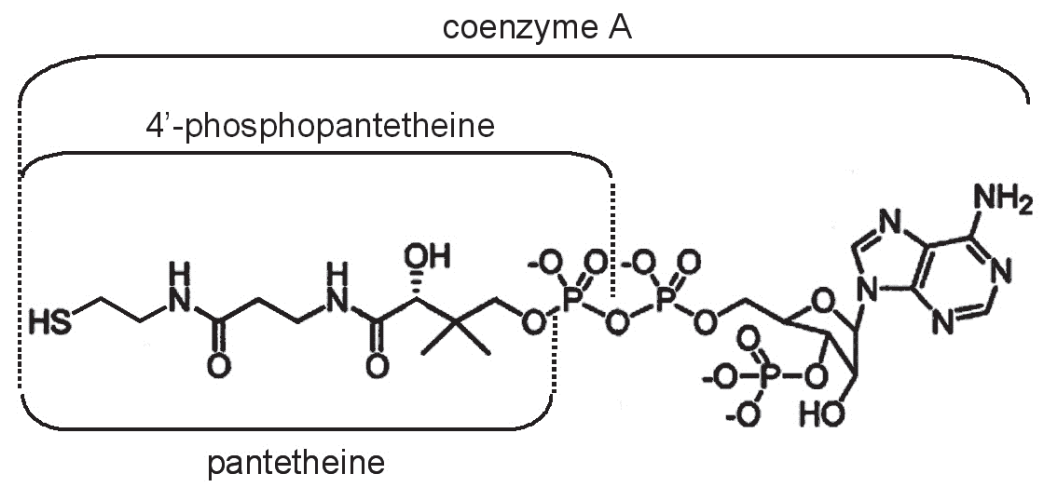

Fig. 2. Pantethine forms the active moiety of CoA. Pantetheine, the reduced form of pantethine, is first $4^{\prime}$-phosphorylated by pantothenate kinase and then adenylated by phosphopantetheine adenylyl transferase (CoaD) to form dephospho-CoA; finally, dephospho-CoA is phosphorylated to coenzyme A by the enzyme dephosphocoenzyme A kinase (CoaE). Lipids are metabolized as fatty acids linked to the SH group of pantetheine, in the form of acyl-CoA thioesters.

\section{Brain energy metabolism}

Although the brain represents only $2 \%$ of the body weight, it receives $15 \%$ of the cardiac output and accounts for $20 \%$ of total body oxygen consumption as well as $25 \%$ of total body glucose utilization. Under physiological conditions, glycolysis is, by far, the major energetic pathway in the adult brain. Glucose is broken down in the presence of oxygen, yielding pyruvate and lactate. Evidence accumulated during the past decade supports the notion that astrocytes play a pivotal role in the regulation of brain-glucose metabolism, via the so-called neuron-astrocyte lactate shuttle (Escartin et al., 2006; Hertz, 2004; Schurr, 2006). Owing to their strategic location surrounding cerebral blood capillaries, astrocytes form the first cellular barrier encountered by glucose entering the brain parenchyma, which makes them a prevalent site of glucose uptake. Blood-borne glucose crosses the vascular endothelial cells and enters brain cells through specific hexose transporters of the glucose transporter family (GLUT) (McEwen and Reagan, 2004; Vannucci et al., 1997). When the supply of oxygen therefore does not match precisely the demand, e.g. during neuronal activation or under pathological conditions, glucose may be broken down anaerobically, to produce lactate in order to supply energy faster. This process has, however, low energetic efficiency.

The following step of energy production is the conversion of pyruvate to acetyl-CoA which is used by mitochondria, the power house of living cells. Mitochondria produce the reductant $\mathrm{NADH}$ via the tricarboxilic acid cycle; then the chemical energy of NADH is used by the electron transport chain (ETC) to synthesize ATP. Mammalian ETC is composed of least 49 individual polypeptides which constitute a series of electron carriers organized in four enzymatic complexes plus the ATP synthase machinery. Complex I (NADH ubiquinone oxidoreductase) (EC1.6.5.3) is a very large enzymatic set catalyzing the first step of the ETC (Saraste, 1999; Schultz and Chan, 2001). The enzyme oxidizes NADH, transferring electrons to Ubiquinone (Coenzyme $\mathrm{Q}, \mathrm{CoQ}$ ), a lipid soluble electron carrier 
embedded in the lipid bilayer of the inner mitochondrial membrane. Complex II (succinateubiquinone oxidoreductase) (EC1.3.5.1), bound to the inner mitochondrial membrane, catalyzes the oxidation of succinate to fumarate with the reduction of ubiquinone to ubiquinol. Complex III (ubiquinol-cytochrome C oxidoreductase; EC 1.10.2.2) is the oligomeric protein complex that transfers electrons from ubiquinol to cytochrome $\mathrm{C}$ and links proton translocation to this electron transfer by the proton motive $\mathrm{Q}$ cycle mechanism (Trumpower, 1990). Complex IV (cytochrome C oxidase (EC 1.9.3.1) is a transmembrane protein which receives electrons from cytochrome $C$ and transfers them to one oxygen molecule, converting molecular oxygen to water. In the whole process, a transmembrane difference of proton electrochemical potential is established that the ATP synthase then uses to synthesize ATP. Mitochondrial dysfunction results in a dwindling supply of ATP, a failure in maintaining cellular homeostasis and activation of cell death pathways.

\section{Energy crisis in Parkinson's disease}

PD, Huntington's disease (HD) and Alzheimer's disease (AD) are age-related diseases of diverse etiologies, but energy crisis is a common factor. The link between PD and mitochondria was first established with the identification of a deficiency in the activity of complex I in the substantia nigra of PD patients (Schapira et al., 1989) and it has been then confirmed by several authors (see reviews in (Banerjee et al., 2009; Schapira, 2006)). Complex I deficiency was noticed not only in the brain but also in the peripheral tissues of PD patients (Krige et al., 1992; Wallace et al., 1992). Whether mitochondrial dysfunction is the cause or effect of PD pathogenesis is debatable. However, it is clear that dopaminergic neurons are especially susceptible to energy deficit, meaning that mitochondrial dysfunction may underlie selective dopaminergic neuro-degeneration in PD (Beal, 2005).

The seminal discovery that MPTP (1-methyl-4-phenyl-1,2,3,6-tetrahydropyridine) causes PDlike symptoms in humans (Langston et al., 1983) and the ensuing rapid unraveling of the molecular mechanism of its toxicity strongly stimulated the interest of the PD research community in the role of mitochondria in PD pathology. MPTP is metabolized to its toxic form $\mathrm{MPP}^{+}$(1-methyl-4-phenylpyridinium ion) by mitochondrial monoamine oxidase (MAO) (Chiba et al., 1984), specifically by MAO B (Heikkila et al., 1984) and is rapidly concentrated in the mitochondria (Ramsay et al., 1986b). Once accumulated, $\mathrm{MPP}^{+}$specifically inhibits the oxidation of NAD-linked substrates (Nicklas et al., 1985) by blocking the electron transfer through the ETC complex I (Ramsay et al., 1986a). It also inhibits the activity of a key TCA (tricarboxylic acid) enzyme KGDHC ( $\alpha$-ketoglutarate dehydrogenase complex) thereby impairing the ATP synthesis and inducing "energy crisis" in vivo (Mizuno et al., 1988b) and in vitro (Mizuno et al., 1988a). The rather selective toxicity of MPP+ to dopaminergic neurons in $\mathrm{SN}$ (substantia nigra) was explained by the fact that MPP+ is selectively accumulated by the dopamine uptake system involving the dopamine transporters (DAT) (Javitch et al., 1985). Platelets which also express DAT (Frankhauser et al., 2006) have been shown to accumulate $\mathrm{MPP}+$ with high efficiency and suffer from mitochondrial failure as a result of MPP+ exposure (Buckman et al., 1988). Human platelets also contain high levels of MAO B and share a number of properties with aminergic neurons including receptors, uptake sites and storage granules for amine neurotransmitters. As platelets are more available for research than PD brain samples or muscle biopsy specimens, they were a natural choice for PD tissue samples in earlier studies on the status of complex I in PD. Low complex I activities have been reported in 
both PD platelet homogenates and mitochondria isolated from PD platelets, although the degree of its inhibition varied within a wide range. Other ETC complexes in PD platelets are also concerned: complex II (Yoshino et al., 1992), complex II + complex III (Haas et al., 1995), and complex IV (Benecke et al., 1993). Several studies showed impaired complex I, II+III, and IV activities in PD muscle (Bindoff et al., 1991; Blin et al., 1994; Cardellach et al., 1993); whereas no differences were observed in other studies (DiDonato et al., 1993; Mann et al., 1992; Reichmann et al., 1994). Similar conflicting results were reported in the ETC in PD lymphocytes (Martin et al., 1996; Yoshino et al., 1992). Such inconsistency in the experimental data may be explained by significant methodological differences in these studies, e.g. difficulties in obtaining the relevant tissue samples, individual variability of PD patients and many other factors, as was suggested (Parker et al., 2008).

Complex I activity is reduced in mitochondria isolated from PD frontal cortex (Keeney et al., 2006; Parker et al., 2008); it is believed to be an early pathogenic event in PD. Ample data strongly suggest that MPTP-induced ETC disruption per se is sufficient to trigger the death of nigrostriatal neurons and to cause PD-like symptoms in animals and humans. Thus, despite some conflicting results, systemic complex I deficiency might be a predominant feature in PD pathogenesis (Banerjee et al., 2009). Accordingly, ${ }^{1} \mathrm{H}$ and ${ }^{31} \mathrm{P}$ magnetic resonance spectrometry demonstrated mitochondrial dysfunction in the putamen and midbrain of both early and advanced PD subjects, with a bilateral reduction of high-energy phosphates; the changes were associated with abnormally elevated lactate levels. In contrast, low-energy metabolites such as adenosine diphophosphate and inorganic phosphate were within normal ranges. These results provide strong in vivo evidence that mitochondrial dysfunction of mesostriatal neurons is a central and persistent phenomenon in the pathogenesis cascade of PD which occurs early in the course of the disease (Hattingen et al., 2009; Henchcliffe et al., 2008).

Paraquat and rotenone are other neurotoxins that inhibit mitochondrial complex I activity, whereas there are substantial differences in their action (Richardson et al., 2005). Rotenone rat models of PD have been developed that reproduce essential biochemical and behavioral human PD features (Alam and Schmidt, 2002; Betarbet et al., 2000; Greenamyre et al., 2003; Sherer et al., 2003).

Complex I activity is redox-dependent and thiol-regulated (Annepu and Ravindranath, 2000; Sriram et al., 1998). Since PD pathogenesis consistently involve reactive oxygen and nitrogen species (Bove et al., 2005; Li et al., 2003; Przedborski, 2005; Przedborski and Ischiropoulos, 2005) this may explain, at least in part, complex I inhibition. Thus, depletion of GSH, an antioxidant and redox modulator, may be one of the early events leading to the inhibition of complex I activity and loss of mitochondrial function (Chinta and Andersen, 2006; Jha et al., 2000).

\section{Mitochondrial dysfunction and the genetic causes of the disease}

In the past decade, a rapidly expanding list of Mendelian-inherited gene mutations has provided great insight into the mechanisms leading to loss of the nigrostriatal dopaminergic neurons in familial PD which constitutes less than $10 \%$ of the total number of PD cases. In recent years, a plethora of studies of the multifunctional consequences of these mutations point towards the disruption of mitochondrial function culminating in neuronal dysfunction and death. 
$\alpha$-Synuclein was the first gene associated with familial PD. It was followed by four other genes linked conclusively to autosomal recessive (parkin, PINK-1, DJ-1) or dominant (LRRK2) Parkinsonism (Bogaerts et al., 2008; Henchcliffe and Beal, 2008).

PINK1. Mutations in phosphatase and tensin homologue (PTEN)-induced putative kinase (PINK1) cause a rare form of autosomal recessive, PD early onset Parkinsonism following the parkin mutations (Valente et al., 2004; Winklhofer and Haass, 2010). Loss of PINK1 function increases the propensity of cells to oxidative stress-induced cell death and imbalance of calcium homeostasis. The experiments suggest that the impairment of mitochondrial calcium efflux promotes ROS formation that inhibits glucose uptake, resulting in reduced substrate delivery and respiration (Gandhi et al., 2009).

Parkin is a multifaceted ubiquitin ligase (Moore, 2006). Mutations in the parkin gene serve as the most common cause of young onset PD (Farrer et al., 2001; Lucking et al., 2000). Loss of function of E3 ligase activity has been suggested to result in accumulation of toxic substrates leading to autosomal recessive form of PD (Dawson, 2006). Parkin gene expression is upregulated in various stress examples and has a wide range of neuroprotective capacities, including protection against mitochondrial dysfunction, endoplasmatic reticulum stress, exitotoxicity, proteasome inhibition, and overexpression of $\alpha$-synuclein, tau, and other proteins. Future studies of the biochemical interactions between PINK1 and parkin and identification of other components in this pathway are likely to provide insight into PD pathogenesis, and might identify new therapeutic targets (Henchcliffe and Beal, 2008).

DJ-1 and LRRK2. DJ-1 has structural similarities with the stress-inducible Escherichia coli chaperone Hsp31 and mutations in the DJ-1 gene are associated with rare cases of early onset autosomal recessive PD (Andersen, 2004). The loss of DJ-1 function leads to a striking sensitivity to the herbicide paraquat and the insecticide rotenone; this suggests that DJ-1 may have a role in the protection from oxidative stress caused by environmental toxins. It has been clearly demonstrated that, while overexpression of DJ-1 protects neurons from oxidative stress-induced damage, conversely DJ-1 deficiency renders cells more susceptible to oxidative injury. Mutations in leucin-rich repeat kinase 2 (LRRK2 gene) cause autosomal dominant PD (Paisan-Ruiz et al., 2004; Zimprich et al., 2004). The precise physiological role of this protein is unknown but the presence of multiple functional domains suggests involvement in a wide variety of functions. A possible mechanism of LRRK2 action is at the mitochondrial level.

\section{Lipids as an alternative carbon source for energy production}

The brain has the ability to use fatty acids as an alternative carbon source. Fatty acid $\beta$ oxidation parallels glycolysis (Fig. 1). This occurs normally during embryonic development and, in adults, under conditions of inadequate glucose supply or increased energy demand, as well as under pathological conditions, such as neurodegeneration, hypoxia/ischemia and traumatic brain injury (Prins, 2008).

\subsection{Lipid metabolism and regulation of mitochondrial function}

Peroxisome Proliferator-Activated Receptors (PPARs) regulate development, tissue differentiation, inflammation, wound healing, mitochondrial function, lipid and glucose metabolism (Reddy et al., 2006; Reddy, 2001). PPARs are expressed in CNS neurons and astrocytes, raising the possibility of exploring the neuroprotective efficacy of PPAR agonists 
in several neurodegenerative disorders (Bordet et al., 2006; Heneka and Landreth, 2007; Woods et al., 2003). Gene-knockout experiments have revealed that, consistent with their distinct expression patterns, each PPAR subtype performs a specific function in fatty acid homeostasis. PPAR- $\alpha$ targets genes function together to coordinate the complex metabolic changes necessary to conserve energy during fasting and feeding in cases where catabolic enzymes promote fatty acid $\beta$-oxidation.

It is now well established that damage to dopaminergic neurons involves oxidative stress, microglial activation-mediated inflammation and mitochondrial impairment, which ultimately culminate in activation of an apoptotic pathway. The PPAR- $\gamma$ agonist pioglitazone was shown to exert protective effects in a mouse model of PD; it attenuated the MPTP intoxication-induced glial activation and prevented dopaminergic cell loss in the substantia nigra pars compacta (Breidert et al., 2002). These findings were paralleled by another study showing that the treatment with pioglitazone may offer an opportunity for treatment of PD to slow its progression (Dehmer et al., 2004).

PPAR- $\gamma$ coactivator $1 \alpha($ PGC- $1 \alpha)$ is a master regulator of mitochondrial biogenesis and respiration (Lehman et al., 2000; Lin et al., 2002; Puigserver et al., 1998; Wu et al., 1999). It transduces many physiological stimuli into specific metabolic programs, often by stimulating mitochondrial activity. For example, PGC- $1 \alpha$ regulates both $\beta$-oxidation of fatty acids and gluconeogenesis in liver (Herzig et al., 2001; Puigserver et al., 2003; Rhee et al., 2003; Yoon et al., 2001). The importance of PGC-1 $\alpha$ in these metabolic programs was further revealed through the generation of PGC- $1 \alpha$ null mice. These mice display a reduced basal expression of many mitochondrial genes in liver, brain, skeletal muscle and heart, compared with wild-type animals (Arany et al., 2005; Leone et al., 2005; Lin et al., 2004). Moreover, it has been shown that PGC-1 $\alpha$ knockout (KO) mice displayed neurodegenerative lesions in the brain, particularly in the striatum; the animals also showed behavioral abnormalities (Leone et al., 2005; Lin et al., 2004). At present, the cause of the brain lesions is unclear, but the lesions observed in many genetic models with altered ROS levels raise the possibility that PGC- $1 \alpha$ plays an important role in the control of ROS in vivo (St-Pierre et al., 2006). PGC-1 $\alpha$ and PGC-1 $\beta$ are powerfully induced by ROS, and these coactivators, in turn, regulate a complex and multifaceted ROS defense system. In the MPTP model, PGC- $1 \alpha$ KO mice have a greatly increased sensitivity to damage by oxidative stress in the dopaminergic cells of the substantia nigra and hippocampal neurons. Conversely, the overexpression of PGC- $1 \alpha$ in cultured dopaminergic neurons from embryonic rat midbrain resulted in activation of electron transport genes and protection against neuronal damage induced by mutant $\alpha$-synuclein (Zheng et al., 2010). The same authors found in postmortem brain tissue samples from PD patients that the gene sets with the strongest association with PD contained nuclear genes encoding subunits of the ETC proteins. These genes all showed decreased expression in substantia nigra dopaminergic neurons even in the earliest stages of PD. Furthermore, a second gene set associated with PD and also underexpressed in the earliest stages of PD encodes enzymes involved in glucose metabolism. These results are compelling because many studies have already implicated dysfunctional mitochondria and altered energy metabolism as well as defective glucose metabolism in PD. The authors realized that these gene sets had in common the master transcriptional regulator, PGC-1 $\alpha$ and surmised that disruption of PGC-1 $\alpha$ expression might be a root cause of PD. 


\subsection{Fatty acid $\beta$-oxidation}

As in the case of glycolysis, the end product of fatty acid $\beta$-oxidation is acetyl-CoA (Fig. 1) which feeds into the TCA cycle to produce energy in the form of NADH and $\mathrm{FADH}_{2}$. The enzymes involved in fatty acid $\beta$-oxidation all act on acyl-CoA, i.e. fatty acids linked to CoA as thioesters. They belong to an oxido-reductase superfamily with broad substrate specificity. The enzymes are subdivided into several groups, according to the substrate chain length. Each of the constituent steps of the pathway comprises three consecutive enzymatic reactions catalyzed by a trifunctional enzymatic complex: 2-enoyl-CoA hydratase, 3-hydroxyacyl-CoA dehydrogenase and 3-ketoacyl-CoA thiolase. The reactions yield acetyl-CoA plus a chain-shortened acyl-CoA (at each step, the fatty acid chain loses two carbons) (Eaton et al., 2000).

In the present review, we focus attention on the penultimate step of the process, i.e. acyl$\mathrm{CoA}$ dehydrogenation. It involves four classes of enzymes: short-chain acyl-CoA dehydrogenase (SCAD, active with $\mathrm{C}_{4}$ and $\mathrm{C}_{6}$ ), medium-chain acyl-CoA dehydrogenase (MCAD, active with $\mathrm{C}_{4}$ to $\mathrm{C}_{12}$ ), long-chain acyl-CoA dehydrogenase (LCAD, active with $\mathrm{C}_{8}$ to $C_{20}$ ) and very-long-chain acyl-CoA dehydrogenase (VLCAD, active with $C_{12}$ to $C_{24}$ ). SCAD, MCAD and LCAD are homotetramers located in the mitochondrial matrix. VLCAD, however, is a homodimer and is located in the inner mitochondrial membrane. VLCAD is a constituent of the trifunctional protein described above.

Short chain 3-hydroxyacyl-CoA dehydrogenase (SCHAD) also known as L-3-hydroxyacylCoA dehydrogenase/amyloid-peptide binding alcohol dehydrogenase (HADH II/ABAD) is predominantly a mitochondrial enzyme (Furuta et al., 1997; Kobayashi et al., 1996) that belongs to the short-chain dehydrogenase/reductase superfamily (Jornvall et al., 1995). It acts on a wide spectrum of substrates, including steroids, cholic acids, and fatty acids, with a preference for short chain methyl-branched acyl-CoAs. Abnormally low or high levels of SCHAD in certain brain regions may contribute to the pathogenesis of some neural disorders. The human SCHAD gene and its protein product are therefore potential targets for intervention in conditions such as $\mathrm{PD}, \mathrm{AD}$ and an X-linked mental retardation, which may arise from the impaired degradation of branched fatty acid chains and of isoleucine (Yang et al., 2005; Zschocke et al., 2000).

The levels of SCHAD/HADH II are significantly reduced in the ventral midbrain of both PD patients and of a PD mouse model generated by MPTP injection (Przedborski et al., 2004). Conversely, transgenic mice with increased expression of human HADH II/ABAD are significantly more resistant to MPTP; overexpression of the enzyme mitigates MPTPinduced impairment of oxidative phosphorylation and ATP production (Tieu et al., 2004). This observation suggests that a new way to prevent PD may be to increase expression of SCHAD/HADH II in the midbrain.

\section{Therapeutic strategies to target the energy crisis}

\subsection{Potential therapeutic compounds}

Coenzyme $\mathbf{Q}(\mathbf{C o Q})$ is a component of the electron transport chain where it accepts electrons from complexes I and II (Beal, 2004). Its administration increases mitochondrial uncoupling protein (UCP) expression in the nervous system of primates, and this is associated with marked neuroprotection in both in vitro and in vivo models of MPTP, paraquat and rotenone-induced mitochondrial dysfunction. $\mathrm{CoQ}_{10}$ exerts significant 
protection against MPTP-induced dopamine depletion and loss of tyrosine hydroxylase immunoreactive neurons in aged mice (Shults et al., 2002).

Creatine is a nitrogenous guanidine compound that helps to supply energy to muscle and nerve cells (Adhihetty and Beal, 2008). Chronic administration of creatine protects against MPTP-induced dopamine loss and improves the survival of neurons in the substantia nigra (Matthews et al., 1999).

$\alpha$-Lipoic acid (ALA) is a disulfide compound found in mitochondria as a coenzyme for pyruvate dehydrogenase and $\alpha$-ketoglutarate dehydrogenase. Dietary supplementation with $\alpha$-lipoic acid in old rats improved ambulatory activity, decreased oxidative damage, and improved mitochondrial function (Hagen et al., 1999). In vitro, pre-treatment of PC12 cells with R-lipoic acid acts to prevent depletion of GSH content and preserves the mitochondrial complex I activity which normally is impaired as a consequence of GSH loss (Bharat et al., 2002).

Carnitine transports long-chain fatty acid into the mitochondrial matrix for subsequent $\beta$-oxidation (Di Lisa et al., 1985; Rosenthal et al., 1992). Carnitine also facilitates the removal of short-chain and medium chain fatty acids that accumulate in the mitochondria during normal and abnormal metabolism. Carnitine and acetyl-L-carnitine attenuate neuronal damage produced by 3-nitropropionic acid, rotenone, and MPTP in vitro (Snyder et al., 1990; Virmani et al., 1995).

Nicotinamide is a precursor of NADH, a substrate for Complex I (NADH-ubiquinone oxidoreductase). It is also an inhibitor of poly-ADP-ribose polymerase, which is activated by DNA damage and in turn depletes both NADH and ATP. Activation of poly-ADP-ribose polymerase plays a role in neuronal injury induced by both ischemia and MPTP (Eliasson et al., 1997; Mandir et al., 1999).

\subsection{Ketone bodies}

If the amounts of acetyl-CoA generated by fatty acid $\beta$-oxidation challenge the processing capacity of the TCA cycle or if activity in the TCA cycle is low, acetyl-CoA is used in the biosynthesis of ketone bodies via $\beta$-hydroxy-metylglutaryl-CoA (HMG-CoA) synthesis. The main ketone bodies are $\mathrm{D}-\beta$-hydroxybutyrate $(\mathrm{D} \beta \mathrm{HB})$ and acetoacetate (ACA). They are produced by hepatocytes and are transported to the tissues, including the brain; astrocytes are also ketogenic, although to a lesser extent (Guzman and Blazquez, 2001).

$\mathrm{D} \beta \mathrm{HB}$ and ACA have a protective role in a broad spectrum of cerebral injuries and diseases and they preserve neuronal cell integrity and stability in vitro. The experimental approaches used are intravenous infusion of mice or rats with D $\beta$ HB (Prins, 2008) or administration of a ketogenic diet (Maalouf et al., 2009). Exogenous ketone bodies have been employed successfully in both rapidly developing pathologies (glutamate excitotoxicity, hypoxia/ischemia) and neurodegenerative conditions (PD, AD) [for review see(Prins, 2008)]. In vitro $\mathrm{D} \beta \mathrm{HB}$ prevents neuronal damage induced by glucose deprivation (Izumi et al., 1998). Following MPP+ exposure, administration of $4 \mathrm{mmol} / \mathrm{L}$ of DBHB increased the survival of cultured neurons (Kashiwaya et al., 2000). In the rotenone in vitro model, application of $8 \mathrm{mmol} / \mathrm{L}$ of $\mathrm{D} \beta \mathrm{HB}$ improved mitochondrial membrane potential and reduced cytochrome $C$ release by mouse neuronal cultures (Imamura et al., 2006); under the same conditions, cell survival was increased by $60 \%$ in human neuroblastoma cell culture. In vivo, $24 \mathrm{~h}$ infusion of $\mathrm{D} \beta \mathrm{HB}$, using mini-osmotic pumps, protected $\mathrm{SNpc}$ dopaminergic neurons against MPTP in a dose-dependent and stereospecific manner and prevented the 
development of PD-like motor abnormalities in mice (Tieu et al., 2003). Tieu's studies provide in vivo and in vitro evidence that $\mathrm{D} \beta \mathrm{HB}$ protects not by alleviating MPTP-related complex I inhibition, but by enhancing oxidative phosphorylation via a mechanism dependent on mitochondrial complex II (succinate-ubiquinone oxidoreductase).

Therefore, modulation of $\mathrm{D} \beta \mathrm{HB}$ levels may be a neuroprotective strategy for the treatment of neurodegenerative diseases such as PD. However, the long-term effects of the chronic use of $\mathrm{D} \beta \mathrm{HB}$ on the cellular metabolism, and especially on mitochondrial function, are not known. D $\beta$ HB has been administered orally for several months to two 6-months-old infants with hyperinsulinemic hypoglycemia (Plecko et al., 2002). The high dosage (up to $32 \mathrm{~g} / \mathrm{d}$ ) seemed to be tolerated by these patients. In addition, ketogenic diets have been used in humans as a treatment for refractory epilepsy. In general, patients tolerate the ketogenic diet well with mild side effects (Freeman et al., 2006). However, long-term ketone therapy will have to take into consideration possible adverse effects.

\subsection{Pantethine}

A promising emerging therapeutic strategy involves fatty acids combined with pantethine. CoA is central in these fields, as illustrated by pantothenate kinase-associated neurodegeneration (PKAN). Pantothenate kinase catalyzes pantetheine phosphorylation to $4^{\prime}$-phosphopantetheine, the first step of CoA synthesis (Fig. 2). PKAN, due to insufficient kinase activity, occurs in early adulthood and its symptoms, such as dystonia, rigidity and tremor, recall PD and it may lead to PD in late adulthood. PKAN results in a decrease of CoA levels associated with mitochondrial dysfunction. These defects can be reversed by pantethine, the oxidized form of pantetheine. Dietary pantethine increased CoA synthesis, improved mitochondrial function, rescued brain degeneration, enhanced locomotor abilities, and increased lifespan in a Drosophila model of PKAN (Rana et al., 2010). Moreover, pantethine circumvented the impairment of fatty acid $\beta$-oxidation in rat liver mitochondria and microvessels of the brain (Morisaki et al., 1983). It has been shown recently that pantethine mitigated MPTP neurotoxicity in the mouse via the enhancement of fatty acid $\beta$-oxidation, leading to increased levels of circulating ketone bodies and improved mitochondrial function (Cornille et al., 2010). In addition, pantethine attenuates MPTPinduced neuroinflammation, as shown by reduced expression of macrophage antigen-1 (MAC-1), a critical trigger of microglial activation associated with neurodegeneration (Pei et al., 2007) (Fig. 3). Ultimately, pantethine protects from MPTP-induced blood-brain barrier (BBB) leakage (Fig. 4) and significantly attenuates the clinical scores (Fig. 5).

\section{Concluding remarks and future perspectives}

Deficits in mitochondrial activity in combination with increased oxidative stress, and agingassociated damage to mitochondrial DNA are key biochemical abnormalities associated with the pathogenesis of not only in sporadic PD but also in familial forms of the disease. Factors that trigger these mitochondrial abnormalities are still elusive, however one may speculate that strategies aimed at correcting these biochemical abnormalities might be useful in halting or slowing down the progression of PD. In this regard some of the candidate drugs which showed great efficacy in experimental models of PD have already made it to clinical trials. Preliminary clinical trial data on Coenzyme Q10 and creatine have shown some promise. There is also a great deal of enthusiasm following the recent identification of 
novel mitochondrial targets such as PGC-1 $\alpha$ and the sirtuin family of enzymes that are known to modulate aging, mitochondrial biogenesis, metabolic homeostasis and mitochondria-dependent cell death. These observations hold promise for future development of neuroprotective strategies in PD by targeting mitochondrial dysfunction. However it is important to remember that PD is a multi-factorial disease and mitochondrial dysfunction may only be a part of this complex process. Future research should thus focus on developing neuroprotective strategies by targeting multiple pathways involved in the disease process. Therapeutic approaches targeting both mitochondrial dysfunction and oxidative damage in neurodegenerative diseases and aging have great promise (Beal, 2005). Pantethine provides an example of molecule able to restore mitochondrial function while displaying antioxidant and anti-inflammatory properties. Perhaps, this safe and effective compound of natural origin merits consideration for broader use against pathologies such as PD.

Control

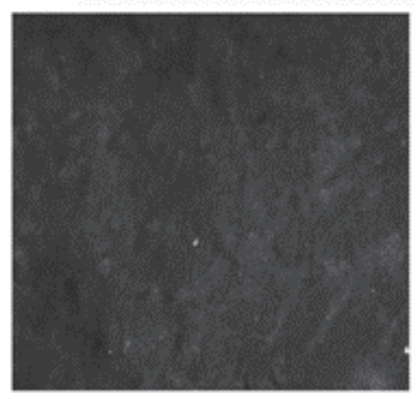

MPTP+saline

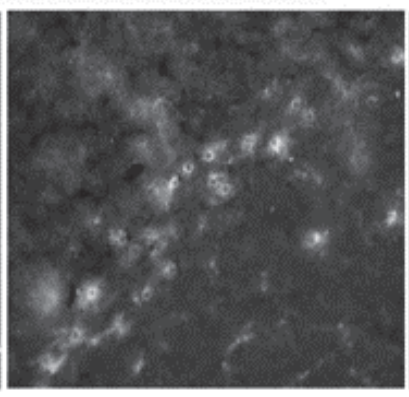

MPTP+pantethine

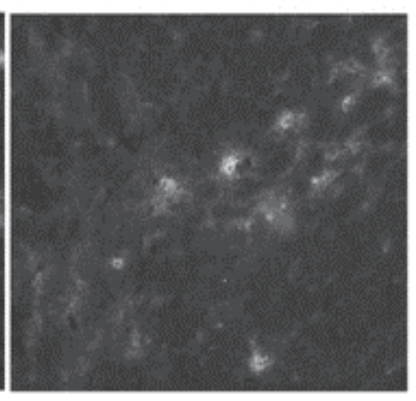

Fig. 3. Attenuation of microglial reaction by pantethine treatment in MPTP-injected mice.

The figure shows macrophage antigen-1 (Mac-1) immunostaining in SNpc, two days after MPTP injection. Microglial reaction was drastically reduced in pantethine-treated mice as compared to saline ones. No immunostaining was observed in control animals.

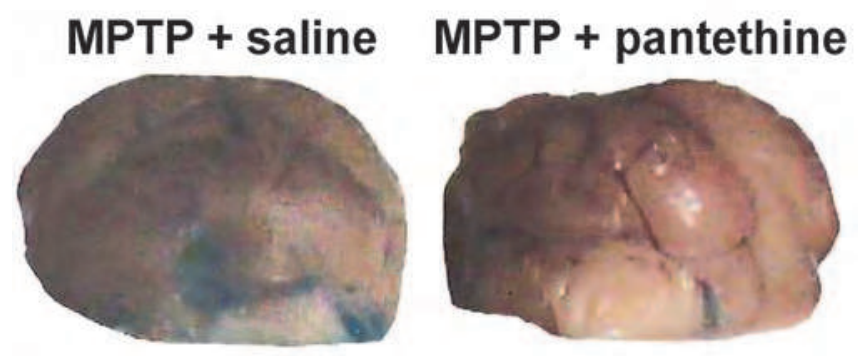

Fig. 4. Prevention of BBB leakage by pantethine treatment in MPTP-injected mice.

Evans blue was administered intravenously on day 16 after MPTP injection. The figure shows brains of saline mice with a diffuse dye leakage, and some intensively stained areas. In contrast, brains of pantethine-treated mice looked normal, with limited stained areas. 


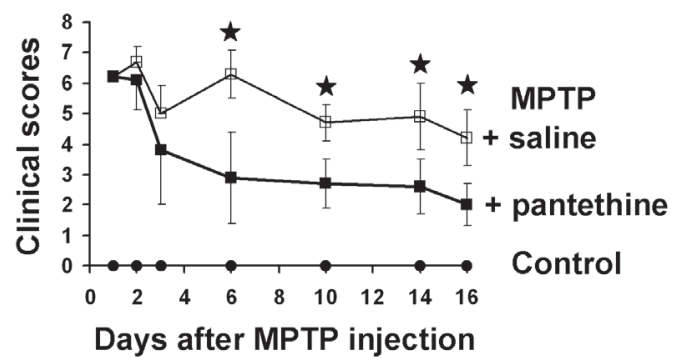

Fig. 5. Attenuation of the clinical scores by pantethine treatment in MPTP-injected mice.

Mice were injected with MPTP and then treated or not treated with pantethine. Under our experimental conditions, the scores were 6.2 in both groups 24 hours after MPTP injection and they decreased much more rapidly in the pantethine group. $\left(^{*}\right)$ Significant difference between the two groups, according to the Student $t$ test $(p<0.01)$.

\section{Acknowledgements}

The authors thank Howard Rickenberg for the critical reading of the manuscript.

\section{References}

Adhihetty, P.J. \& Beal, M.F. (2008). Creatine and its potential therapeutic value for targeting cellular energy impairment in neurodegenerative diseases. Neuromolecular Medicine, Vol.10, pp. 275-290

Alam, M. \& Schmidt, W.J. (2002). Rotenone destroys dopaminergic neurons and induces parkinsonian symptoms in rats. behavioural brain research, Vol.136, pp. 317-324

Andersen, J.K. (2004). Oxidative stress in neurodegeneration: cause or consequence? Nature Medicine, Vol.10 Suppl, pp. S18-25

Annepu, J. \& Ravindranath, V. (2000). 1-Methyl-4-phenyl-1,2,3,6-tetrahydropyridineinduced complex I inhibition is reversed by disulfide reductant, dithiothreitol in mouse brain. Neuroscience Letters, Vol.289, pp. 209-212

Arany, Z.; He, H.; Lin, J.; Hoyer, K.; Handschin, C.; Toka, O.; Ahmad, F.; Matsui, T.; Chin, S.; Wu, P.H.; Rybkin, II; Shelton, J.M.; Manieri, M.; Cinti, S.; Schoen, F.J.; Bassel-Duby, R.; Rosenzweig, A.; Ingwall, J.S.\& Spiegelman, B.M. (2005). Transcriptional coactivator PGC-1 alpha controls the energy state and contractile function of cardiac muscle. Cell Metabolism, Vol.1, pp. 259-271

Banerjee, R.; Starkov, A.A.; Beal, M.F.\& Thomas, B. (2009). Mitochondrial dysfunction in the limelight of Parkinson's disease pathogenesis. Biochimica et Biophysica Acta, Vol.1792, pp. 651-663

Beal, M.F. (2004). Therapeutic effects of coenzyme Q10 in neurodegenerative diseases. Methods in Enzymology, Vol.382, pp. 473-487

Beal, M.F. (2005). Mitochondria take center stage in aging and neurodegeneration. Annals of Neurology, Vol.58, pp. 495-505 
Benecke, R.; Strumper, P.\& Weiss, H. (1993). Electron transfer complexes I and IV of platelets are abnormal in Parkinson's disease but normal in Parkinson-plus syndromes. Brain, Vol.116 ( Pt 6), pp. 1451-1463

Betarbet, R.; Sherer, T.B.; MacKenzie, G.; Garcia-Osuna, M.; Panov, A.V.\& Greenamyre, J.T. (2000). Chronic systemic pesticide exposure reproduces features of Parkinson's disease. Nature Neuroscience, Vol.3, pp. 1301-1306

Bharat, S.; Cochran, B.C.; Hsu, M.; Liu, J.; Ames, B.N.\& Andersen, J.K. (2002). Pre-treatment with R-lipoic acid alleviates the effects of GSH depletion in PC12 cells: implications for Parkinson's disease therapy. Neurotoxicology, Vol.23, pp. 479-486

Bindoff, L.A.; Birch-Machin, M.A.; Cartlidge, N.E.; Parker, W.D., Jr.\& Turnbull, D.M. (1991). Respiratory chain abnormalities in skeletal muscle from patients with Parkinson's disease. Journal of the Neurological Sciences, Vol.104, pp. 203-208

Blin, O.; Desnuelle, C.; Rascol, O.; Borg, M.; Peyro Saint Paul, H.; Azulay, J.P.; Bille, F.; Figarella, D.; Coulom, F.; Pellissier, J.F.\& et al. (1994). Mitochondrial respiratory failure in skeletal muscle from patients with Parkinson's disease and multiple system atrophy. Journal of the Neurological Sciences, Vol.125, pp. 95-101

Bogaerts, V.; Theuns, J.\& van Broeckhoven, C. (2008). Genetic findings in Parkinson's disease and translation into treatment: a leading role for mitochondria? Genes, Brain and behavior, Vol.7, pp. 129-151

Bordet, R.; Gele, P.; Duriez, P.\& Fruchart, J.C. (2006). PPARs: a new target for neuroprotection. Journal of Neurology, Neurosurgery and Psychiatry, Vol.77, pp. 285287

Bove, J.; Prou, D.; Perier, C.\& Przedborski, S. (2005). Toxin-induced models of Parkinson's disease. NeuroRx, Vol.2, pp. 484-494

Breidert, T.; Callebert, J.; Heneka, M.T.; Landreth, G.; Launay, J.M.\& Hirsch, E.C. (2002). Protective action of the peroxisome proliferator-activated receptor-gamma agonist pioglitazone in a mouse model of Parkinson's disease. Journal of Neurochemistry, Vol.82, pp. 615-624

Buckman, T.D.; Chang, R.; Sutphin, M.S.\& Eiduson, S. (1988). Interaction of 1-methyl-4phenylpyridinium ion with human platelets. Biochemical and Biophysical Research Communications, Vol.151, pp. 897-904

Cardellach, F.; Marti, M.J.; Fernandez-Sola, J.; Marin, C.; Hoek, J.B.; Tolosa, E.\& UrbanoMarquez, A. (1993). Mitochondrial respiratory chain activity in skeletal muscle from patients with Parkinson's disease. Neurology, Vol.43, pp. 2258-2262

Chiba, K.; Trevor, A.\& Castagnoli, N., Jr. (1984). Metabolism of the neurotoxic tertiary amine, MPTP, by brain monoamine oxidase. Biochemical and Biophysical Research Communications, Vol.120, pp. 574-578

Chinta, S.J. \& Andersen, J.K. (2006). Reversible inhibition of mitochondrial complex I activity following chronic dopaminergic glutathione depletion in vitro: implications for Parkinson's disease. Free Radical Biology and Medicine, Vol.41, pp. 1442-1448

Cornille, E.; Abou-Hamdan, M.; Khrestchatisky, M.; Nieoullon, A.; de Reggi, M.\& Gharib, B. (2010). Enhancement of L-3-hydroxybutyryl-CoA dehydrogenase activity and circulating ketone body levels by pantethine. Relevance to dopaminergic injury. BMC Neuroscience, Vol.11, pp. 51

Dawson, T.M. (2006). Parkin and defective ubiquitination in Parkinson's disease. Journal of Neural Transmission Supplementa, pp. 209-213 
Dehmer, T.; Heneka, M.T.; Sastre, M.; Dichgans, J.\& Schulz, J.B. (2004). Protection by pioglitazone in the MPTP model of Parkinson's disease correlates with I kappa B alpha induction and block of NF kappa B and iNOS activation. Journal of Neurochemistry, Vol.88, pp. 494-501

Di Lisa, F.; Bobyleva-Guarriero, V.; Jocelyn, P.; Toninello, A.\& Siliprandi, N. (1985). Stabilising action of carnitine on energy linked processes in rat liver mitochondria. Biochemical and Biophysical Research Communications, Vol.131, pp. 968-973

DiDonato, S.; Zeviani, M.; Giovannini, P.; Savarese, N.; Rimoldi, M.; Mariotti, C.; Girotti, F.\& Caraceni, T. (1993). Respiratory chain and mitochondrial DNA in muscle and brain in Parkinson's disease patients. Neurology, Vol.43, pp. 2262-2268

Eaton, S.; Bursby, T.; Middleton, B.; Pourfarzam, M.; Mills, K.; Johnson, A.W.\& Bartlett, K. (2000). The mitochondrial trifunctional protein: centre of a beta-oxidation metabolon? Biochemical Society Transactions, Vol.28, pp. 177-182

Eliasson, M.J.; Sampei, K.; Mandir, A.S.; Hurn, P.D.; Traystman, R.J.; Bao, J.; Pieper, A.; Wang, Z.Q.; Dawson, T.M.; Snyder, S.H.\& Dawson, V.L. (1997). Poly(ADP-ribose) polymerase gene disruption renders mice resistant to cerebral ischemia. Nature Medicine, Vol.3, pp. 1089-1095

Escartin, C.; Valette, J.; Lebon, V.\& Bonvento, G. (2006). Neuron-astrocyte interactions in the regulation of brain energy metabolism: a focus on NMR spectroscopy. Journal of Neurochemistry, Vol.99, pp. 393-401

Farrer, M.; Chan, P.; Chen, R.; Tan, L.; Lincoln, S.; Hernandez, D.; Forno, L.; Gwinn-Hardy, K.; Petrucelli, L.; Hussey, J.; Singleton, A.; Tanner, C.; Hardy, J.\& Langston, J.W. (2001). Lewy bodies and parkinsonism in families with parkin mutations. Annals of Neurology, Vol.50, pp. 293-300

Frankhauser, P.; Grimmer, Y.; Bugert, P.; Deuschle, M.; Schmidt, M.\& Schloss, P. (2006). Characterization of the neuronal dopamine transporter DAT in human blood platelets. Neuroscience Letters, Vol.399, pp. 197-201

Freeman, J.; Veggiotti, P.; Lanzi, G.; Tagliabue, A.\& Perucca, E. (2006). The ketogenic diet: from molecular mechanisms to clinical effects. Epilepsy Research, Vol.68, pp. 145-180

Furuta, S.; Kobayashi, A.; Miyazawa, S.\& Hashimoto, T. (1997). Cloning and expression of cDNA for a newly identified isozyme of bovine liver 3-hydroxyacyl-CoA dehydrogenase and its import into mitochondria. Biochimica et Biophysica Acta, Vol.1350, pp. 317-324

Gandhi, S.; Wood-Kaczmar, A.; Yao, Z.; Plun-Favreau, H.; Deas, E.; Klupsch, K.; Downward, J.; Latchman, D.S.; Tabrizi, S.J.; Wood, N.W.; Duchen, M.R.\& Abramov, A.Y. (2009). PINK1-associated Parkinson's disease is caused by neuronal vulnerability to calcium-induced cell death. Molecular Cell, Vol.33, pp. 627-638

Greenamyre, J.T.; Betarbet, R.\& Sherer, T.B. (2003). The rotenone model of Parkinson's disease: genes, environment and mitochondria. Parkinsonism and Related Disorders, Vol.9 Suppl 2, pp. S59-64

Guzman, M. \& Blazquez, C. (2001). Is there an astrocyte-neuron ketone body shuttle? Trends Endocrinol Metab, Vol.12, pp. 169-173

Haas, R.H.; Nasirian, F.; Nakano, K.; Ward, D.; Pay, M.; Hill, R.\& Shults, C.W. (1995). Low platelet mitochondrial complex I and complex II/III activity in early untreated Parkinson's disease. Annals of Neurology, Vol.37, pp. 714-722 
Hagen, T.M.; Ingersoll, R.T.; Lykkesfeldt, J.; Liu, J.; Wehr, C.M.; Vinarsky, V.; Bartholomew, J.C.\& Ames, A.B. (1999). (R)-alpha-lipoic acid-supplemented old rats have improved mitochondrial function, decreased oxidative damage, and increased metabolic rate. Faseb Journal, Vol.13, pp. 411-418

Hattingen, E.; Magerkurth, J.; Pilatus, U.; Mozer, A.; Seifried, C.; Steinmetz, H.; Zanella, F.\& Hilker, R. (2009). Phosphorus and proton magnetic resonance spectroscopy demonstrates mitochondrial dysfunction in early and advanced Parkinson's disease. Brain, Vol.132, pp. 3285-3297

Heikkila, R.E.; Manzino, L.; Cabbat, F.S.\& Duvoisin, R.C. (1984). Protection against the dopaminergic neurotoxicity of 1-methyl-4-phenyl-1,2,5,6-tetrahydropyridine by monoamine oxidase inhibitors. Nature, Vol.311, pp. 467-469

Henchcliffe, C. \& Beal, M.F. (2008). Mitochondrial biology and oxidative stress in Parkinson disease pathogenesis. Nature Clinical Practive Neurology, Vol.4, pp. 600-609

Henchcliffe, C.; Shungu, D.C.; Mao, X.; Huang, C.; Nirenberg, M.J.; Jenkins, B.G.\& Beal, M.F. (2008). Multinuclear magnetic resonance spectroscopy for in vivo assessment of mitochondrial dysfunction in Parkinson's disease. Annals of the New York Academy of Sciences, Vol.1147, pp. 206-220

Heneka, M.T. \& Landreth, G.E. (2007). PPARs in the brain. Biochimica et Biophysica Acta, Vol.1771, pp. 1031-1045

Hertz, L. (2004). The astrocyte-neuron lactate shuttle: a challenge of a challenge. Journal of Cerebral Blood Flow and Metabolism, Vol.24, pp. 1241-1248

Herzig, S.; Long, F.; Jhala, U.S.; Hedrick, S.; Quinn, R.; Bauer, A.; Rudolph, D.; Schutz, G.; Yoon, C.; Puigserver, P.; Spiegelman, B.\& Montminy, M. (2001). CREB regulates hepatic gluconeogenesis through the coactivator PGC-1. Nature, Vol.413, pp. 179183

Imamura, K.; Takeshima, T.; Kashiwaya, Y.; Nakaso, K.\& Nakashima, K. (2006). D-betahydroxybutyrate protects dopaminergic SH-SY5Y cells in a rotenone model of Parkinson's disease. Journal of Neuroscience Research, Vol.84, pp. 1376-1384

Izumi, Y.; Ishii, K.; Katsuki, H.; Benz, A.M.\& Zorumski, C.F. (1998). beta-Hydroxybutyrate fuels synaptic function during development. Histological and physiological evidence in rat hippocampal slices. Journal of Clinical Investigation, Vol.101, pp. 1121-1132

Javitch, J.A.; D'Amato, R.J.; Strittmatter, S.M.\& Snyder, S.H. (1985). Parkinsonism-inducing neurotoxin, N-methyl-4-phenyl-1,2,3,6 -tetrahydropyridine: uptake of the metabolite N-methyl-4-phenylpyridine by dopamine neurons explains selective toxicity. Proceedings of the National Academy of Sciences of the U S A, Vol.82, pp. 21732177

Jha, N.; Jurma, O.; Lalli, G.; Liu, Y.; Pettus, E.H.; Greenamyre, J.T.; Liu, R.M.; Forman, H.J.\& Andersen, J.K. (2000). Glutathione depletion in PC12 results in selective inhibition of mitochondrial complex I activity. Implications for Parkinson's disease. Journal of Biological Chemistry, Vol.275, pp. 26096-26101

Jornvall, H.; Persson, B.; Krook, M.; Atrian, S.; Gonzalez-Duarte, R.; Jeffery, J.\& Ghosh, D. (1995). Short-chain dehydrogenases/reductases (SDR). Biochemistry, Vol.34, pp. 6003-6013

Kashiwaya, Y.; Takeshima, T.; Mori, N.; Nakashima, K.; Clarke, K.\& Veech, R.L. (2000). Dbeta-hydroxybutyrate protects neurons in models of Alzheimer's and Parkinson's 
disease. Proceedings of the National Academy of Sciences of the U S A, Vol.97, pp. 54405444

Keeney, P.M.; Xie, J.; Capaldi, R.A.\& Bennett, J.P., Jr. (2006). Parkinson's disease brain mitochondrial complex I has oxidatively damaged subunits and is functionally impaired and misassembled. J Neurosci, Vol.26, pp. 5256-5264

Kobayashi, A.; Jiang, L.L.\& Hashimoto, T. (1996). Two mitochondrial 3-hydroxyacyl-CoA dehydrogenases in bovine liver. J Biochem, Vol.119, pp. 775-782

Krige, D.; Carroll, M.T.; Cooper, J.M.; Marsden, C.D.\& Schapira, A.H. (1992). Platelet mitochondrial function in Parkinson's disease. The Royal Kings and Queens Parkinson Disease Research Group. Annals of Neurology, Vol.32, pp. 782-788

Langston, J.W.; Ballard, P.; Tetrud, J.W.\& Irwin, I. (1983). Chronic Parkinsonism in humans due to a product of meperidine-analog synthesis. Science, Vol.219, pp. 979-980

Lehman, J.J.; Barger, P.M.; Kovacs, A.; Saffitz, J.E.; Medeiros, D.M.\& Kelly, D.P. (2000). Peroxisome proliferator-activated receptor gamma coactivator-1 promotes cardiac mitochondrial biogenesis. Journal of Clinical Investigation, Vol.106, pp. 847-856

Leone, T.C.; Lehman, J.J.; Finck, B.N.; Schaeffer, P.J.; Wende, A.R.; Boudina, S.; Courtois, M.; Wozniak, D.F.; Sambandam, N.; Bernal-Mizrachi, C.; Chen, Z.; Holloszy, J.O.; Medeiros, D.M.; Schmidt, R.E.; Saffitz, J.E.; Abel, E.D.; Semenkovich, C.F.\& Kelly, D.P. (2005). PGC-1alpha deficiency causes multi-system energy metabolic derangements: muscle dysfunction, abnormal weight control and hepatic steatosis. PLoS Biolology, Vol.3, pp. e101

Li, N.; Ragheb, K.; Lawler, G.; Sturgis, J.; Rajwa, B.; Melendez, J.A.\& Robinson, J.P. (2003). Mitochondrial complex I inhibitor rotenone induces apoptosis through enhancing mitochondrial reactive oxygen species production. Journal of Biological Chemistry, Vol.278, pp. 8516-8525

Lin, J.; Wu, H.; Tarr, P.T.; Zhang, C.Y.; Wu, Z.; Boss, O.; Michael, L.F.; Puigserver, P.; Isotani, E.; Olson, E.N.; Lowell, B.B.; Bassel-Duby, R.\& Spiegelman, B.M. (2002). Transcriptional co-activator PGC-1 alpha drives the formation of slow-twitch muscle fibres. Nature, Vol.418, pp. 797-801

Lin, J.; Wu, P.H.; Tarr, P.T.; Lindenberg, K.S.; St-Pierre, J.; Zhang, C.Y.; Mootha, V.K.; Jager, S.; Vianna, C.R.; Reznick, R.M.; Cui, L.; Manieri, M.; Donovan, M.X.; Wu, Z.; Cooper, M.P.; Fan, M.C.; Rohas, L.M.; Zavacki, A.M.; Cinti, S.; Shulman, G.I.; Lowell, B.B.; Krainc, D.\& Spiegelman, B.M. (2004). Defects in adaptive energy metabolism with CNS-linked hyperactivity in PGC-1alpha null mice. Cell, Vol.119, pp. 121-135

Lucking, C.B.; Durr, A.; Bonifati, V.; Vaughan, J.; De Michele, G.; Gasser, T.; Harhangi, B.S.; Meco, G.; Denefle, P.; Wood, N.W.; Agid, Y.\& Brice, A. (2000). Association between early-onset Parkinson's disease and mutations in the parkin gene. New England Journal of Medicine, Vol.342, pp. 1560-1567

Maalouf, M.; Rho, J.M.\& Mattson, M.P. (2009). The neuroprotective properties of calorie restriction, the ketogenic diet, and ketone bodies. Brain Research Reviews, Vol.59, pp. 293-315

Mandir, A.S.; Przedborski, S.; Jackson-Lewis, V.; Wang, Z.Q.; Simbulan-Rosenthal, C.M.; Smulson, M.E.; Hoffman, B.E.; Guastella, D.B.; Dawson, V.L.\& Dawson, T.M. (1999). Poly(ADP-ribose) polymerase activation mediates 1-methyl-4-phenyl-1, 
2,3,6-tetrahydropyridine (MPTP)-induced parkinsonism. Proceedings of the National Academy of Sciences of the U S A, Vol.96, pp. 5774-5779

Mann, V.M.; Cooper, J.M.; Krige, D.; Daniel, S.E.; Schapira, A.H.\& Marsden, C.D. (1992). Brain, skeletal muscle and platelet homogenate mitochondrial function in Parkinson's disease. Brain, Vol.115 ( Pt 2), pp. 333-342

Martin, M.A.; Molina, J.A.; Jimenez-Jimenez, F.J.; Benito-Leon, J.; Orti-Pareja, M.; Campos, Y.\& Arenas, J. (1996). Respiratory-chain enzyme activities in isolated mitochondria of lymphocytes from untreated Parkinson's disease patients. Grupo-Centro de Trastornos del Movimiento. Neurology, Vol.46, pp. 1343-1346

Matthews, R.T.; Ferrante, R.J.; Klivenyi, P.; Yang, L.; Klein, A.M.; Mueller, G.; KaddurahDaouk, R.\& Beal, M.F. (1999). Creatine and cyclocreatine attenuate MPTP neurotoxicity. Experimental Neurology, Vol.157, pp. 142-149

McEwen, B.S. \& Reagan, L.P. (2004). Glucose transporter expression in the central nervous system: relationship to synaptic function. European Journal of Pharmacology, Vol.490, pp. 13-24

Mizuno, Y.; Sone, N.; Suzuki, K.\& Saitoh, T. (1988a). Studies on the toxicity of 1-methyl-4phenylpyridinium ion (MPP+) against mitochondria of mouse brain. Journal of the Neurological Sciences, Vol.86, pp. 97-110

Mizuno, Y.; Suzuki, K.; Sone, N.\& Saitoh, T. (1988b). Inhibition of mitochondrial respiration by 1-methyl-4-phenyl-1,2,3,6-tetrahydropyridine (MPTP) in mouse brain in vivo. Neuroscience Letters, Vol.91, pp. 349-353

Moore, D.J. (2006). Parkin: a multifaceted ubiquitin ligase. Biochemical Society Transactions, Vol.34, pp. 749-753

Morisaki, N.; Matsuoka, N.; Shirai, K.; Sasaki, N.; Saito, Y.\& Kumagai, A. (1983). Effect of pantethine on fatty acid oxidation in microvessels of rat brain. Tohoku Journal of Experimental Medicine, Vol.141, pp. 41-45

Nicklas, W.J.; Vyas, I.\& Heikkila, R.E. (1985). Inhibition of NADH-linked oxidation in brain mitochondria by 1-methyl-4-phenyl-pyridine, a metabolite of the neurotoxin, 1methyl-4-phenyl-1,2,5,6-tetrahydropyridine. Life Sciences, Vol.36, pp. 2503-2508

Paisan-Ruiz, C.; Jain, S.; Evans, E.W.; Gilks, W.P.; Simon, J.; van der Brug, M.; Lopez de Munain, A.; Aparicio, S.; Gil, A.M.; Khan, N.; Johnson, J.; Martinez, J.R.; Nicholl, D.; Carrera, I.M.; Pena, A.S.; de Silva, R.; Lees, A.; Marti-Masso, J.F.; Perez-Tur, J.; Wood, N.W.\& Singleton, A.B. (2004). Cloning of the gene containing mutations that cause PARK8-linked Parkinson's disease. Neuron, Vol.44, pp. 595-600

Parker, W.D., Jr.; Parks, J.K.\& Swerdlow, R.H. (2008). Complex I deficiency in Parkinson's disease frontal cortex. Brain Research, Vol.1189, pp. 215-218

Pei, Z.; Pang, H.; Qian, L.; Yang, S.; Wang, T.; Zhang, W.; Wu, X.; Dallas, S.; Wilson, B.; Reece, J.M.; Miller, D.S.; Hong, J.S.\& Block, M.L. (2007). MAC1 mediates LPSinduced production of superoxide by microglia: the role of pattern recognition receptors in dopaminergic neurotoxicity. Glia, Vol.55, pp. 1362-1373

Plecko, B.; Stoeckler-Ipsiroglu, S.; Schober, E.; Harrer, G.; Mlynarik, V.; Gruber, S.; Moser, E.; Moeslinger, D.; Silgoner, H.\& Ipsiroglu, O. (2002). Oral beta-hydroxybutyrate supplementation in two patients with hyperinsulinemic hypoglycemia: monitoring of beta-hydroxybutyrate levels in blood and cerebrospinal fluid, and in the brain by in vivo magnetic resonance spectroscopy. Pediatric Research, Vol.52, pp. 301-306 
Prins, M.L. (2008). Cerebral metabolic adaptation and ketone metabolism after brain injury. Journal of Cerebral Blood Flow and Metabolism, Vol.28, pp. 1-16

Przedborski, S. (2005). Pathogenesis of nigral cell death in Parkinson's disease. Parkinsonism and Related Disorders, Vol.11 Suppl 1, pp. S3-7

Przedborski, S. \& Ischiropoulos, H. (2005). Reactive oxygen and nitrogen species: weapons of neuronal destruction in models of Parkinson's disease. Antioxidants and Redox Signaling, Vol.7, pp. 685-693

Przedborski, S.; Tieu, K.; Perier, C.\& Vila, M. (2004). MPTP as a mitochondrial neurotoxic model of Parkinson's disease. Journal of Bioenergetics and Biomembranes, Vol.36, pp. 375-379

Puigserver, P.; Rhee, J.; Donovan, J.; Walkey, C.J.; Yoon, J.C.; Oriente, F.; Kitamura, Y.; Altomonte, J.; Dong, H.; Accili, D.\& Spiegelman, B.M. (2003). Insulin-regulated hepatic gluconeogenesis through FOXO1-PGC-1alpha interaction. Nature, Vol.423, pp. 550-555

Puigserver, P.; Wu, Z.; Park, C.W.; Graves, R.; Wright, M.\& Spiegelman, B.M. (1998). A coldinducible coactivator of nuclear receptors linked to adaptive thermogenesis. Cell, Vol.92, pp. 829-839

Ramsay, R.R.; Salach, J.I.; Dadgar, J.\& Singer, T.P. (1986a). Inhibition of mitochondrial NADH dehydrogenase by pyridine derivatives and its possible relation to experimental and idiopathic parkinsonism. Biochemical and Biophysical Research Communications, Vol.135, pp. 269-275

Ramsay, R.R.; Salach, J.I.\& Singer, T.P. (1986b). Uptake of the neurotoxin 1-methyl-4phenylpyridine (MPP+) by mitochondria and its relation to the inhibition of the mitochondrial oxidation of NAD+-linked substrates by MPP+. Biochemical and Biophysical Research Communications, Vol.134, pp. 743-748

Rana, A.; Seinen, E.; Siudeja, K.; Muntendam, R.; Srinivasan, B.; van der Want, J.J.; Hayflick, S.; Reijngoud, D.J.; Kayser, O.\& Sibon, O.C. (2010). Pantethine rescues a Drosophila model for pantothenate kinase-associated neurodegeneration. Proceedings of the National Academy of Sciences of the U S A, Vol.107, pp. 6988-6993

Reddy, H.K.; Koshy, S.K.; Wasson, S.; Quan, E.E.; Pagni, S.; Roberts, A.M.; Joshua, I.G.\& Tyagi, S.C. (2006). Adaptive-outward and maladaptive-inward arterial remodeling measured by intravascular ultrasound in hyperhomocysteinemia and diabetes. Journal of Cardiovascular Pharmacology and Therapeutics, Vol.11, pp. 65-76

Reddy, J.K. (2001). Nonalcoholic steatosis and steatohepatitis. III. Peroxisomal betaoxidation, PPAR alpha, and steatohepatitis. American Journal of Physiology. Gastrointestinal and Liver Physiology, Vol.281, pp. G1333-1339

Reichmann, H.; Janetzky, B.; Bischof, F.; Seibel, P.; Schols, L.; Kuhn, W.\& Przuntek, H. (1994). Unaltered respiratory chain enzyme activity and mitochondrial DNA in skeletal muscle from patients with idiopathic Parkinson's syndrome. European Neurology, Vol.34, pp. 263-267

Rhee, J.; Inoue, Y.; Yoon, J.C.; Puigserver, P.; Fan, M.; Gonzalez, F.J.\& Spiegelman, B.M. (2003). Regulation of hepatic fasting response by PPARgamma coactivator-1alpha (PGC-1): requirement for hepatocyte nuclear factor 4alpha in gluconeogenesis. Proceedings of the National Academy of Sciences of the U S A, Vol.100, pp. 4012-4017 
Richardson, J.R.; Quan, Y.; Sherer, T.B.; Greenamyre, J.T.\& Miller, G.W. (2005). Paraquat neurotoxicity is distinct from that of MPTP and rotenone. Toxicological Sciences, Vol.88, pp. 193-201

Rosenthal, R.E.; Chanderbhan, R.; Marshall, G.\& Fiskum, G. (1992). Prevention of postischemic brain lipid conjugated diene production and neurological injury by hydroxyethyl starch-conjugated deferoxamine. Free Radical Biology and Medicine, Vol.12, pp. 29-33

Saraste, M. (1999). Oxidative phosphorylation at the fin de siecle. Science, Vol.283, pp. 14881493

Schapira, A.H. (2006). Mitochondrial disease. Lancet, Vol.368, pp. 70-82

Schapira, A.H.; Cooper, J.M.; Dexter, D.; Jenner, P.; Clark, J.B.\& Marsden, C.D. (1989). Mitochondrial complex I deficiency in Parkinson's disease. Lancet, Vol.1, pp. 1269

Schultz, B.E. \& Chan, S.I. (2001). Structures and proton-pumping strategies of mitochondrial respiratory enzymes. Annual Review of Biophysics and Biomolecular Structure, Vol.30, pp. $23-65$

Schurr, A. (2006). Lactate: the ultimate cerebral oxidative energy substrate? Journal of Cerebral Blood Flow \& Metabolism, Vol.26, pp. 142-152

Sherer, T.B.; Betarbet, R.; Testa, C.M.; Seo, B.B.; Richardson, J.R.; Kim, J.H.; Miller, G.W.; Yagi, T.; Matsuno-Yagi, A.\& Greenamyre, J.T. (2003). Mechanism of toxicity in rotenone models of Parkinson's disease. J Neurosci, Vol.23, pp. 10756-10764

Shults, C.W.; Oakes, D.; Kieburtz, K.; Beal, M.F.; Haas, R.; Plumb, S.; Juncos, J.L.; Nutt, J.; Shoulson, I.; Carter, J.; Kompoliti, K.; Perlmutter, J.S.; Reich, S.; Stern, M.; Watts, R.L.; Kurlan, R.; Molho, E.; Harrison, M.\& Lew, M. (2002). Effects of coenzyme Q10 in early Parkinson disease: evidence of slowing of the functional decline. Archives of Neurology, Vol.59, pp. 1541-1550

Snyder, J.W.; Kyle, M.E.\& Ferraro, T.N. (1990). L-carnitine delays the killing of cultured hepatocytes by 1-methyl-4-phenyl-1,2,3,6-tetrahydropyridine. Archives of Biochemistry and Biophysics, Vol.276, pp. 132-138

Sriram, K.; Shankar, S.K.; Boyd, M.R.\& Ravindranath, V. (1998). Thiol oxidation and loss of mitochondrial complex I precede excitatory amino acid-mediated neurodegeneration. J Neurosci, Vol.18, pp. 10287-10296

St-Pierre, J.; Drori, S.; Uldry, M.; Silvaggi, J.M.; Rhee, J.; Jager, S.; Handschin, C.; Zheng, K.; Lin, J.; Yang, W.; Simon, D.K.; Bachoo, R.\& Spiegelman, B.M. (2006). Suppression of reactive oxygen species and neurodegeneration by the PGC-1 transcriptional coactivators. Cell, Vol.127, pp. 397-408

Tieu, K.; Perier, C.; Caspersen, C.; Teismann, P.; Wu, D.C.; Yan, S.D.; Naini, A.; Vila, M.; Jackson-Lewis, V.; Ramasamy, R.\& Przedborski, S. (2003). D-beta-hydroxybutyrate rescues mitochondrial respiration and mitigates features of Parkinson disease. Journal of Clinical Investigation, Vol.112, pp. 892-901

Tieu, K.; Perier, C.; Vila, M.; Caspersen, C.; Zhang, H.P.; Teismann, P.; Jackson-Lewis, V.; Stern, D.M.; Yan, S.D.\& Przedborski, S. (2004). L-3-hydroxyacyl-CoA dehydrogenase II protects in a model of Parkinson's disease. Annals of Neurology, Vol.56, pp. 51-60

Trumpower, B.L. (1990). The protonmotive Q cycle. Energy transduction by coupling of proton translocation to electron transfer by the cytochrome bc1 complex. Journal of Biological Chemistry, Vol.265, pp. 11409-11412 
Valente, E.M.; Abou-Sleiman, P.M.; Caputo, V.; Muqit, M.M.; Harvey, K.; Gispert, S.; Ali, Z.; Del Turco, D.; Bentivoglio, A.R.; Healy, D.G.; Albanese, A.; Nussbaum, R.; Gonzalez-Maldonado, R.; Deller, T.; Salvi, S.; Cortelli, P.; Gilks, W.P.; Latchman, D.S.; Harvey, R.J.; Dallapiccola, B.; Auburger, G.\& Wood, N.W. (2004). Hereditary early-onset Parkinson's disease caused by mutations in PINK1. Science, Vol.304, pp. 1158-1160

Vannucci, S.J.; Maher, F.\& Simpson, I.A. (1997). Glucose transporter proteins in brain: delivery of glucose to neurons and glia. Glia, Vol.21, pp. 2-21

Virmani, M.A.; Biselli, R.; Spadoni, A.; Rossi, S.; Corsico, N.; Calvani, M.; Fattorossi, A.; De Simone, C.\& Arrigoni-Martelli, E. (1995). Protective actions of L-carnitine and acetyl-L-carnitine on the neurotoxicity evoked by mitochondrial uncoupling or inhibitors. Pharmacological Research, Vol.32, pp. 383-389

Wallace, D.C.; Shoffner, J.M.; Watts, R.L.; Juncos, J.L.\& Torroni, A. (1992). Mitochondrial oxidative phosphorylation defects in Parkinson's disease. Annals of Neurology, Vol.32, pp. 113-114

Winklhofer, K.F. \& Haass, C. (2010). Mitochondrial dysfunction in Parkinson's disease. Biochimica et Biophysica Acta, Vol.1802, pp. 29-44

Woods, J.W.; Tanen, M.; Figueroa, D.J.; Biswas, C.; Zycband, E.; Moller, D.E.; Austin, C.P.\& Berger, J.P. (2003). Localization of PPARdelta in murine central nervous system: expression in oligodendrocytes and neurons. Brain Research, Vol.975, pp. 10-21

Wu, Z.; Puigserver, P.; Andersson, U.; Zhang, C.; Adelmant, G.; Mootha, V.; Troy, A.; Cinti, S.; Lowell, B.; Scarpulla, R.C.\& Spiegelman, B.M. (1999). Mechanisms controlling mitochondrial biogenesis and respiration through the thermogenic coactivator PGC-1. Cell, Vol.98, pp. 115-124

Yang, S.Y.; He, X.Y.\& Schulz, H. (2005). 3-Hydroxyacyl-CoA dehydrogenase and short chain 3-hydroxyacyl-CoA dehydrogenase in human health and disease. FEBS Journal, Vol.272, pp. 4874-4883

Yoon, J.C.; Puigserver, P.; Chen, G.; Donovan, J.; Wu, Z.; Rhee, J.; Adelmant, G.; Stafford, J.; Kahn, C.R.; Granner, D.K.; Newgard, C.B.\& Spiegelman, B.M. (2001). Control of hepatic gluconeogenesis through the transcriptional coactivator PGC-1. Nature, Vol.413, pp. 131-138

Yoshino, H.; Nakagawa-Hattori, Y.; Kondo, T.\& Mizuno, Y. (1992). Mitochondrial complex I and II activities of lymphocytes and platelets in Parkinson's disease. Journal of Neural Transmission.Parkinson's disease and Dementia Section, Vol.4, pp. 27-34

Zheng, B. et al. (2010). PGC-1alpha, a potential therapeutic target for early intervention in Parkinson's disease. Science Translational Medicine, Vol.2, pp. 52ra73

Zimprich, A. et al.(2004). Mutations in LRRK2 cause autosomal-dominant parkinsonism with pleomorphic pathology. Neuron, Vol.44, pp. 601-607

Zschocke, J.; Ruiter, J.P.; Brand, J.; Lindner, M.; Hoffmann, G.F.; Wanders, R.J.\& Mayatepek, E. (2000). Progressive infantile neurodegeneration caused by 2-methyl-3hydroxybutyryl-CoA dehydrogenase deficiency: a novel inborn error of branchedchain fatty acid and isoleucine metabolism. Pediatric Research, Vol.48, pp. 852-855 


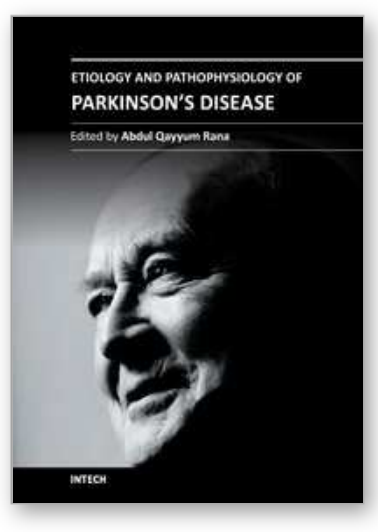

\section{Etiology and Pathophysiology of Parkinson's Disease}

Edited by Prof. Abdul Qayyum Rana

ISBN 978-953-307-462-7

Hard cover, 542 pages

Publisher InTech

Published online 12, October, 2011

Published in print edition October, 2011

This book about Parkinsonâ $€^{\mathrm{TM}} \mathrm{S}$ disease provides a detailed account of etiology and pathophysiology of Parkinsonâ€ ${ }^{\mathrm{TM}} \mathrm{s}$ disease, a complicated neurological condition. Environmental and genetic factors involved in the causation of Parkinsonâ€ ${ }^{\mathrm{TM}} \mathrm{S}$ disease have been discussed in detail. This book can be used by basic scientists as well as researchers. Neuroscience fellows and life science readers can also obtain sufficient information. Beside genetic factors, other pathophysiological aspects of Parkinsonâ $€^{\mathrm{TM}} \mathrm{s}$ disease have been discussed in detail. Up to date information about the changes in various neurotransmitters, inflammatory responses, oxidative pathways and biomarkers has been described at length. Each section has been written by one or more faculty members of well known academic institutions. Thus, this book brings forth both clinical and basic science aspects of Parkinsonâ€ ${ }^{\mathrm{TM}} \mathrm{S}$ disease.

\section{How to reference}

In order to correctly reference this scholarly work, feel free to copy and paste the following:

Mhamad Abou-Hamdan, Emilie Cornille, Michel Khrestchatisky, Max de Reggi and Bouchra Gharib (2011). The Energy Crisis in Parkinson's Disease: A Therapeutic Target, Etiology and Pathophysiology of Parkinson's Disease, Prof. Abdul Qayyum Rana (Ed.), ISBN: 978-953-307-462-7, InTech, Available from: http://www.intechopen.com/books/etiology-and-pathophysiology-of-parkinson-s-disease/the-energy-crisis-inparkinson-s-disease-a-therapeutic-target

\section{INTECH}

open science | open minds

\author{
InTech Europe \\ University Campus STeP Ri \\ Slavka Krautzeka 83/A \\ 51000 Rijeka, Croatia \\ Phone: +385 (51) 770447 \\ Fax: +385 (51) 686166 \\ www.intechopen.com
}

\author{
InTech China \\ Unit 405, Office Block, Hotel Equatorial Shanghai \\ No.65, Yan An Road (West), Shanghai, 200040, China \\ 中国上海市延安西路65号上海国际贵都大饭店办公楼 405 单元 \\ Phone: +86-21-62489820 \\ Fax: $+86-21-62489821$
}


(C) 2011 The Author(s). Licensee IntechOpen. This is an open access article distributed under the terms of the Creative Commons Attribution 3.0 License, which permits unrestricted use, distribution, and reproduction in any medium, provided the original work is properly cited. 